F. Child Lang. 40 (2013), 29-46. (C) Cambridge University Press 2012.

The online version of this article is published within an Open Access environment subject to the conditions of the Creative Commons Attribution-NonCommercial-ShareAlike licence $<$ http://creativecommons.org/licenses/by-nc-sa/2.5/ $>$. The written permission of Cambridge University Press must be obtained for commercial re-use.

doi:10.1017/So305000912000086

\title{
Failure to learn from feedback underlies word learning difficulties in toddlers at risk for autism
}

\author{
R. BEDFORD
}

Centre for Research in Autism and Education, Department of Psychology and Human Development, Institute of Education, London

T. GLIGA

Centre for Brain and Cognitive Development, Birkbeck, University of London

$$
\text { K. FRAME }
$$

Centre for Research in Autism and Education, Department of Psychology and Human Development, Institute of Education, London

$$
\text { K. HUDRY }
$$

Olga Tennison Autism Research Centre, School of Psychological Science, La Trobe University, Australia

\section{S. CHANDLER}

Centre for Research in Autism and Education, Department of Psychology and Human Development, Institute of Education, London

\section{H. JOH NSON}

Centre for Brain and Cognitive Development, Birkbeck, University of London

$$
\text { T. CHARMAN }
$$

Centre for Research in Autism and Education, Department of Psychology and Human Development, Institute of Education, London

AND

THE BASIS TEAM*

(Received 7 August 201 I - Revised 22 December 201 I - Accepted I6 February 2012)

[*] The BASIS Team (alphabetically): Simon Baron-Cohen, Patrick Bolton, Mayada Elsabbagh, Janice Fernandes, Holly Garwood, Greg Pasco, Leslie Tucker, Agnes Volein. 


\section{ABSTRACT}

Children's assignment of novel words to nameless objects, over objects whose names they know (mutual exclusivity; ME) has been described as a driving force for vocabulary acquisition. Despite their ability to use ME to fast-map words (Preissler \& Carey, 2005), children with autism show impaired language acquisition. We aimed to address this puzzle by building on studies showing that correct referent selection using ME does not lead to word learning unless ostensive feedback is provided on the child's object choice (Horst \& Samuelson, 2008). We found that although toddlers aged 2; 0 at risk for autism can use ME to choose the correct referent of a word, they do not benefit from feedback for long-term retention of the word-object mapping. Further, their difficulty using feedback is associated with their smaller receptive vocabularies. We propose that difficulties learning from social feedback, not lexical principles, limits vocabulary building during development in children at risk for autism.

When studying how children learn words, we are faced with the famous Quinean puzzle - how do children know which of the many objects in their visual field is the referent of a word they hear (i.e. referent indeterminacy; Quine, I960)? Young language learners have many available strategies that help them to solve this correspondence problem throughout development. Earlier on, rich ostensive and referential cues are needed for children to acquire their first words; the caregiver or experimenter must ostensively direct the child's attention to an object and repeatedly label it (Hollich et al., 2000; Houston-Price, Plunkett \& Duffy, 2006; Woodward \& Hoyne, r 999). Later in development, word learning has been demonstrated in the absence of such cues, in which case infants make use of various heuristics to infer a speaker's referent. One such heuristic - the mutual exclusivity (ME) principle - refers to the assumption that novel words refer to unfamiliar objects or objects for which the child does not yet have a label. Most children start using this principle towards the end of their second year of life (Halberda, 2003; Markman \& Wachtel, r 988). It is believed that children

\footnotetext{
We are very grateful for the enormous contributions BASIS families have made towards this study. We thank Natasa Ganea for helping with data analysis. The research is supported by a Bloomsbury Colleges Scholarship to R. Bedford, the BASIS funding consortium led by Autistica (www.basisnetwork.org), Autism Speaks (PI M. H. Johnson, Grant number I 292) and a UK Medical Research Council Programme Grant (Go7o I 484) to M. H. Johnson. The Centre for Research in Autism and Education is supported by The Clothworkers' Foundation and Pears Foundation. T. Charman and M. Elsabbagh are supported by the COST Action BMroo4. Address for correspondence: Rachael Bedford, Centre for Research in Autism and Education, Department of Psychology and Human Development, Institute of Education, 25 Woburn Square, London, WC I H ०AA, London, UK.e-mail: r.bedford@ioe.ac.uk
} 
learn the ME principle by noticing that objects tend to be referred to using only one name (Markman, I99I). When exceptions occur, as in bilingual environments, children are less likely to treat object names as mutually exclusive (e.g. Davidson, Jergovic, Imami \& Theodos, I997). Because a word-object association appears to be possible after only one labelling episode (Carey \& Bartlett, I 978), word learning in this context is referred to as FAST MAPPING, and has frequently been described as a driving force of the 'vocabulary explosion' seen at the end of the second year of life (e.g. Markman, Wasow \& Hansen, 2003).

However, more recently, a few studies have challenged the central role given to referent selection through ME for vocabulary growth (Horst \& Samuelson, 2008; Mather \& Plunkett, 20I I). A typical ME task presents the children with two or more objects, one of which is unfamiliar. The child is asked to retrieve or to look at the dax (or another pseudo-word) (Halberda, 2003; Merriman \& Schuster, I99 I). Correct referent selection (either taking the novel object or looking longer at it) is in this case taken to reflect correct word learning. However, this differs from the testing of word learning and retention in ostensive word learning situations. In this latter case, looking at the referred object while it is labelled may only reflect cue following and is therefore not considered sufficient evidence. Correct word-object mapping is typically tested in a separate trial, following the labelling episode, with the child asked to choose the correct referent of a newly learned word amongst two previously labelled objects (Gliga, Elsabbagh, Hudry, Charman Johnson \& the BASIS Team, in press; Houston-Price et al., 2006). When a similar procedure has been used to test word retention following fast mapping, results have been surprisingly negative. Horst and Samuelson (2008) showed that toddlers who were successful at using $\mathrm{ME}$ to choose the correct referent of a new word performed at chance when asked to retrieve that object 5 minutes later. Interestingly, the children's performance in the retention trials improved if, after their initial correct choice, the experimenter reinforced their knowledge by ostensively labelling the object (i.e. by holding the object while pointing to it and naming it). These findings suggest that applying the ME principle may be necessary for quickly finding the referent of a new word but is not sufficient for that word to enter the child's vocabulary. On the contrary, feedback upon the child's initial choice seems to be crucial in creating a long-term word-object mapping.

Apart from adding to our understanding of word learning mechanisms, these findings have the potential to clarify a contentious issue in language acquisition in autism. Children with autism spectrum disorder (ASD) are less responsive to social cues, in particular to referential cues (Fletcher-Watson, Leekam, Benson, Frank \& Findlay, 2009; Leekam \& Ramsden, 2006), and experimental studies have shown that they have 
difficulties using such cues for word learning (Baron-Cohen, Baldwin \& Crowson, I 997). However, referent selection through ME seems to be intact in this population (de Marchena, Eigsti, Worek, Ono \& Snedeker, 20 I I; Preissler \& Carey, 2005). This seems surprising given that children with autism have smaller vocabularies than expected for their age (Charman, Drew, Baird \& Baird, 2003; Hudry et al., 2010; Tager-Flusberg, Paul \& Lord, 2005), and further that delays in language acquisition (not accompanied by non-verbal gestural communication) form part of the diagnostic criteria for ASD (ICD-ı; WHO, I993). There are two possible explanations for this discrepancy. First, it could be that studies have overestimated these children's referent selection abilities. Because autism is rarely diagnosed before two years of age, ME has mostly been assessed in older children (Preissler \& Carey, 2005, tested five- to nine-year-olds; de Marchena et al., $20 \mathrm{II}$, assessed children aged seven to eleven years). Their ability to use the ME constraint might have been the result of an extended learning process and therefore not a contributor to word learning earlier in development. Despite their age and proven ME skills, average comprehension vocabulary in Preissler and Carey's (2005) sample was equivalent only to that of a typical two-year-old. A second explanation for the discrepancy between vocabulary size and word learning strategies may be explained by possible word retention difficulties. It could be that children with ASD, who are less sensitive to social-communicative cues, do not benefit from ostensive feedback and are therefore less able to retain the word-object mapping, despite their demonstrated ability to use the ME bias.

To tease apart these hypotheses we replicated Horst and Samuelson's (2008) study with a sample of two-year-olds who were either at high or low risk for ASD. Later-born siblings of children with ASD are at increased genetic risk of having an ASD themselves (henceforth high-risk children), relative to infants with no such family history (low-risk children) (Bolton et al., 1994; Constantino, Zhang, Frazier, Abbacchi \& Law, 2010). Although only a proportion of high-risk children will go on to develop an ASD, a much greater number are expected to manifest subclinical ASD-like atypicalities (Ozonoff, Rogers, Farnham \& Pennington, I993; Rogers, 2009), including language difficulties (Piven, Palmer, Landa, Santangelo, Jacobi \& Childress, I 997). The few studies that have examined language development in high-risk children show that they are slower to acquire language (Toth, Dawson, Meltzoff, Greenson \& Fein, 2007; Yirmiya, Gamliel, Pilowsky, Feldman, Baron-Cohen \& Sigman, 2006; Yirmiya, Gamliel, Shaked \& Sigman, 2007). There are, however, few studies that have investigated WORD-LEARNING strategies in this population. We know that high-risk three-year-olds have difficulties using ostensive and referential cues to learn a new word-object mapping (Gliga et al., in press), but little is known about available strategies earlier in development. Studying two-year-olds at high 
risk for ASD enables us to investigate whether the linguistic difficulties measured in this population are related (I) to difficulties with referent selection through ME, apparent earlier in development (but not later in life; Preissler \& Carey, 2005) or (2) to difficulties using feedback for long-term word retention. We first assessed children's ability to fast map a novel word to an unfamiliar object. Following each trial choice, we either provided no feedback, or ostensively labelled the novel object, thus correcting or reinforcing the child's initial choice. Word knowledge was retested after a 5-minute break.

\section{METHODS}

Ethical approval was given by NHS NRES London REC (o8/Ho7 I 8/76) and parents gave informed consent.

\section{Participants}

Thirty-one toddlers at high risk for ASD and forty-four low-risk children took part in this study. Six additional children (one low-risk, five high-risk) participated but were not included in the analysis due to non-compliance. To take account of the non-verbal IQ differences $(t(7 \mathrm{I})=3 \cdot 28, p=0.002)$, data for thirteen low-risk toddlers were removed, including two children who had no Mullen Scales of Early Learning (MSEL; Mullen, 1995) data and the eleven children with the highest non-verbal scores. Following exclusion, $M S E L$ non-verbal scores did not differ significantly between the groups $(t(52 \cdot 5)=\mathrm{I} \cdot 68, p=\cdot \mathrm{I})$. Participants included in the final analysis were thirty-one low-risk toddlers ( 13 boys and I 8 girls, mean age $=24 \cdot 3$ months, $S D=0.59$ ) and thirty-one high-risk toddlers ( 4 boys and I 7 girls, mean age $=24.6$ months, $S D=\mathrm{I} \cdot 02)$. All toddlers were participating in a longitudinal study, the British Autism Study of Infant Siblings (BASIS). Exclusion criteria at intake for both groups included medical or neurological conditions and sensory or motor problems.

Children were considered at high risk for ASD by virtue of having an older brother or sister (proband) with a community clinical diagnosis of ASD. Twenty-six probands were male, and five were female. Diagnosis of the proband was confirmed by two expert clinicians (TC, PB) using the Development and Wellbeing Assessment (DAWBA; Goodman, Ford, Richards, Gatward \& Meltzer, 2000) and the parent-report Social Communication Questionnaire (SCQ; (Rutter, Bailey \& Lord, 2003). Most probands met criteria for ASD on both the DAWBA and SCQ $(n=27)$. While one proband scored below threshold on the SCQ, no exclusions were made, due to meeting threshold on the DAWBA and expert opinion. For three probands, data were only available for either the DAWBA $(n=\mathrm{I})$ or 
the SCQ $(n=2)$. For one proband, neither measure was available (aside from parent-confirmed local clinical ASD diagnosis at intake). Parentreported family medical histories were examined for significant medical conditions in the proband or extended families members, with no exclusions made on this basis. The DAWBA is a parent-completed, Web-based questionnaire that combines symptom ratings and narrative description that is then reviewed by an expert clinician. It was used to establish the prevalence of pervasive developmental disorders (ASD) in the UK national children and adolescent mental health survey (Fombonne, 2003). The SCQ is a parent-completed questionnaire with questions developed from the Autism Diagnostic Interview-Revised (ADI-R; Lord, Rutter \& LeCouteur, I994). Children in the low-risk group were recruited from a volunteer database at Birkbeck, Centre for Brain and Cognitive Development. All low-risk infants had at least one older sibling; eighteen male and thirteen female. Screening for possible ASD in these older siblings was undertaken using the SCQ, with all children scoring below the instrument cut-off for ASD ( $\leqslant$ I $\left._{5}\right)$.

\section{Stimuli}

Stimuli for the word-learning task were sixteen familiar objects, eight of which were designated 'target familiar' (spoon, toy duck, key, toy horse, ball, toy car, baby shoe, toy pig) and eight of which were designated 'non-target familiar' (toy cow, cup, toothbrush, pen, hairbrush, book, fork, comb). An additional eight novel objects were similarly either 'target novel' or 'non-target novel' (egg poacher, bottle stopper, lemon juicer, avocado slicer, bottle opener, cooking brush, fried egg shaper, whisk). The 'target familiar' objects were chosen based on the normative MacArthur Bates Communicative Development Inventory (CDI) estimates for two-year-olds (Dale \& Fenson, I996) with all object labels reported to be known by at least $76 \%$ of toddlers at that age. For the 'target novel' objects, four novel, bisyllabic, pseudo-words were used: moxi, fimit, kela and togo. The twenty-four objects available were then split into groups of three for each trial, with two familiar objects, and one novel object. Each child completed eight trials, four with 'target familiar' items (Familiar trials) and four with a 'target novel' item (Novel trials). In the Familiar trials, a 'target familiar' object was paired with another 'non-target familiar' object and a 'non-target novel' object. In the Novel trials, the 'target novel' object was paired with two 'non-target familiar' items. Care was taken to ensure that none of the 'non-target familiar' objects names were phonologically close to the name used for the novel object. Two alternative options for the assignment of groups of objects to the trial types were created and use of one or the other option was counterbalanced across children in the 


\section{$8 \times$ Fast-mapping}

$(4 \times$ Familiar $)$

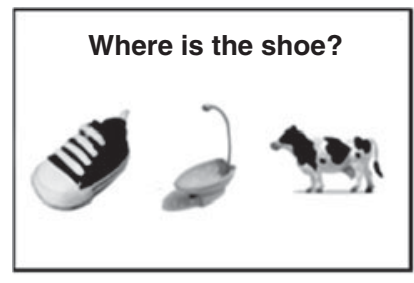

'thank you'
$(4 \times$ Novel $)$

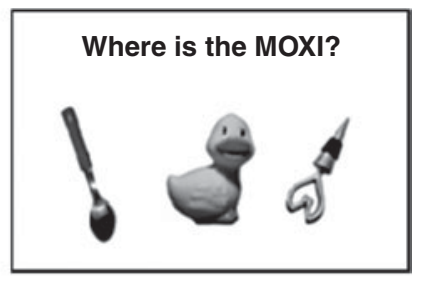

'thank you'

'this is the MOXI'

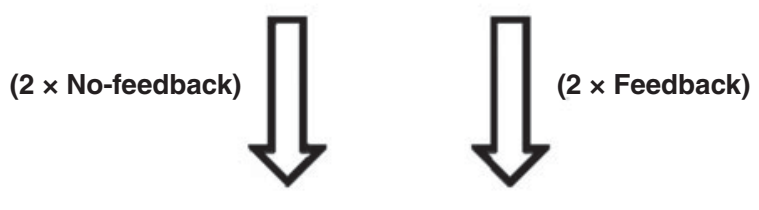

$4 \times$ Retention

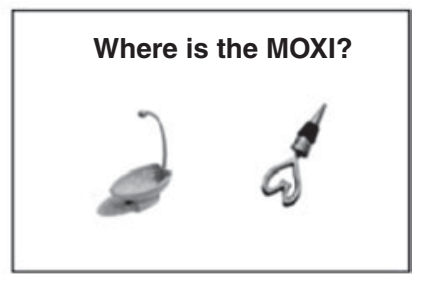

Fig. I. Experimental paradigm. Example of objects and words used in the fast-mapping and retention trials.

two groups. The objects were presented to children on an unpartitioned rectangular tray.

\section{Procedure and design}

The study was split into three phases: FAMILIARIZATION with the objects, FAST-MAPPING and, following a 5-minute delay, RETENTION (see Figure I). During the initial familiarization period, children played with all of the objects for 5 minutes to ensure that novelty preference would not interfere with children's later choices in the experimental task (Mather \& Plunkett, 2010). An experimenter made sure that the child saw all of the objects by asking the child to place the objects one by one into a box. No objects were named, during this phase, by either the experimenter or the parent. The experimental task then began, with the child seated at a small table, either alone or on the parent's lap, facing the experimenter. 
Fast-mapping trials. At the start of each trial the experimenter held the tray of objects and, looking at the child, said "Can you see the spoon/ moxi?" The tray was then placed in front of the child and the experimenter asked "Can you give me the spoon/moxi?" On all Familiar trials and on two of the Novel trials the experimenter responded "Thank you”, irrespective of which object the child chose. These were therefore 'No-feedback' trials. In the remaining two Novel trials (i.e. Feedback trials) the experimenter ostensively labelled the correct object, holding it in front of the child and responding either "Yes, this is the moxi. What a nice moxi!" or "No, this is the moxi. What a nice moxi" depending on whether the child's choice had been correct or incorrect.

Retention trials. Following a 5-minute break during which children played in the testing room with other toys, there were four retention trials. Pairs of only Novel objects were presented, each including a 'target novel' object and a 'non-target novel' object (which had been seen during familiarization and the Familiar fast-mapping trials, but which had never been named). Previously target novel objects were paired with non-targets so that we can test memory for all four target objects, independently. For two of the retention trials, the 'target novel' object had previously been ostensively labelled during fast mapping (Feedback trials), while the other two trials had included no labelling (No-feedback trials). Retention trials again followed one of two predetermined orders, with selection counterbalanced across children.

\section{Data analysis}

Children's responses were video coded during both the fast-mapping and retention trials. If the child made no response (i.e. did not touch or give any of the objects), then the trial was discarded as invalid. Valid trials were coded as correct or incorrect on the basis of the object given by the child to the examiner (or, if no object was given, then on the basis of the first object touched by the child). A second coder rated trials for four high-risk ( $3 \%$ ) and four low-risk ( $3 \%$ ) toddlers, yielding го०\% agreement between coders.

\section{Measures of language and general development}

General developmental level was assessed at the same visit, using the MSEL (low-risk $n=3 \mathrm{I}$, high-risk $n=3 \mathrm{I}$ ). A non-verbal composite score was calculated as the average of the Visual Reception and Fine Motor scale T-scores. The CDI (Fenson et al., I993), a parent report measure of vocabulary, was also collected for toddlers in both groups (low-risk $n=30$, high-risk $n=26$ ). A receptive vocabulary count was calculated by combining 
TABLE i. Group descriptives

\begin{tabular}{lll}
\hline & Low-risk $(n=3 \mathrm{I})$ & High-risk $(n=3 \mathrm{I})$ \\
\hline Age & $24 \cdot 3(0 \cdot 59)$ & $24 \cdot 6(\mathrm{I} \cdot 0)$ \\
F:M & $\mathrm{I}: \mathrm{I} 3$ & $\mathrm{I} 7: \mathrm{I} 4$ \\
CDI & $(n=30)$ & $(n=26)$ \\
Receptive vocabulary count & $449 \cdot 0(\mathrm{I} 72 \cdot \mathrm{I})$ & $335 \cdot 2(\mathrm{I} 66 \cdot 8) *$ \\
Mullen & $(n=3 \mathrm{I})$ & $(n=3 \mathrm{I})$ \\
Non-verbal ability (T-score) & $53.58(7 \cdot 03)$ & $49 \cdot 79(\mathrm{I0} \cdot 45)$ \\
Verbal ability (T-score) & $57.55(7 \cdot 74)$ & $50 \cdot \mathrm{I} 2(\mathrm{I} 2 \cdot 39)^{*}$ \\
\hline
\end{tabular}

NOTE: * indicates that scores are significantly different at the $p<\cdot 05$ level.

the total numbers of words 'understood' and words 'understood and said' for each child. Group characteristics are shown in Table I.

\section{RESULTS}

We analyze separately the fast-mapping and the retention trials. In each case, we used a mixed-factorial ANOVA to test for differences in word learning performance as a result of Group (varying between-subjects; lowrisk, high-risk), and fast-mapping Item type (varying within-subjects; Novel, Familiar) or retention Feedback type (also varying within-subjects; Feedback, No-feedback). The number of valid trials did not differ significantly between Groups (Novel item: High-Risk $M=3 \cdot 9$, Low-Risk $M=4 \cdot 0$; Familiar item: High-Risk $M=3 \cdot 9$, Low-Risk $M=4 \cdot 0$; Ostensive feedback: High-Risk $M=\mathrm{I} \cdot 9$, Low-Risk $M=\mathrm{I} \cdot 9$; No-feedback: High-Risk $M=2 \cdot 0$, Low-Risk $M=\mathrm{I} \cdot 9)$. We also compare performance to chance levels to highlight for which group and under which conditions participants successfully choose the correct referent or remembered its label. We subsequently reanalyzed retention data by separating those trials for which ostensive feedback provided either a correction of an initially incorrect choice or reinforcement of an initially correct choice. ${ }^{1}$

\section{Fast-mapping}

One sample $t$-tests against a chance level of 0.33 showed that both low-risk and high-risk toddlers performed significantly above chance in selecting the correct object in both Novel and Familiar fast-mapping trials (low-risk

[I] Because of the greater number of girls in the low-risk group and the frequently reported superiority of girls' language skills (observed also in this study with girls' average receptive vocabularies of $47 \mathrm{I}$ words, whereas for boys this was 295 words $(t(54)=-p<\cdot 00 \mathrm{I}))$, we have initially entered Gender as a between-subjects factor in all statistical analyses. However, Gender did not affect the significance level of any main factors of interest (Trial, Group), nor did it significantly interact with them. As such, we have collapsed across gender in the analysis presented here. 


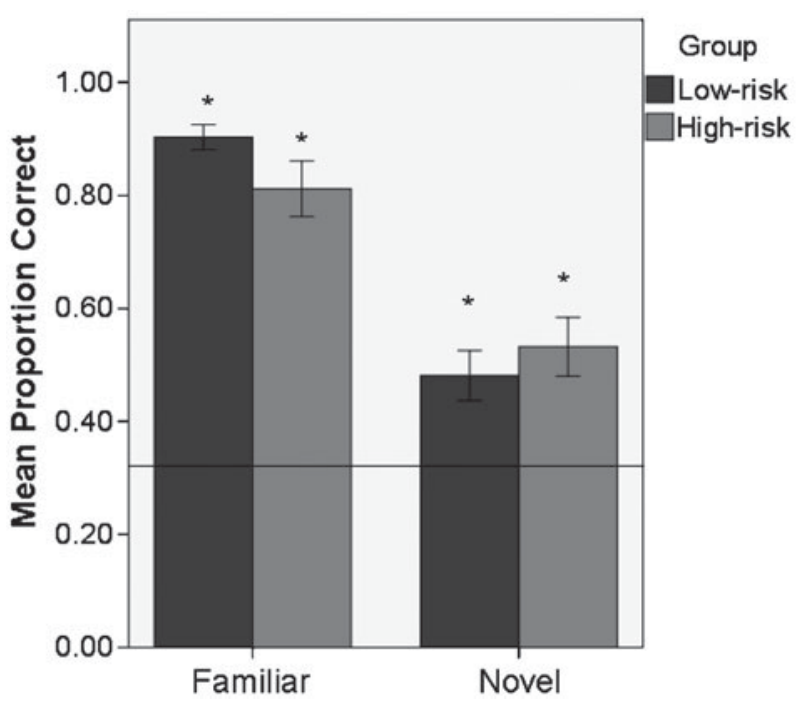

Fig. 2. Performance during the fast-mapping trials (chance level is 0.33 ; error bars $+/ \mathbf{I}_{\mathbf{I}}$ standard error; * indicates performance significantly above chance at the $p<\cdot 0_{5}$ level).

novel: $t(30)=3 \cdot 4 \mathrm{I}, \quad p=\cdot 002$, low-risk familiar: $t(30)=25 \cdot 78, p<\cdot \circ \circ \mathrm{I}$; high-risk novel: $t(30)=3.88, p=\cdot 00 \mathrm{I}$, high-risk familiar: $t(30)=9 \cdot 77$, $p<\cdot 00 \mathrm{I}$; see Figure 2 ).

A mixed-factorial ANOVA revealed a significant main effect of Trial $\left(F(\mathrm{I}, 60)=84 \cdot 20, p<\cdot 00 \mathrm{I}, \eta p^{2}=\cdot 58\right)$, with both groups showing superior performance on Familiar trials, but no significant main effect of Group $\left(F(\mathrm{I}, 60)=0 \cdot 17, p>\cdot \mathrm{I}, \eta p^{2}=\cdot 003\right)$. High-risk toddlers performed slightly worse than controls on familiar item trials and slightly better than low-risk controls on novel item trials, but the Trial by Group interaction was not significant $\left(F(\mathrm{I}, 60)=3 \cdot 47, p=\cdot 07, \eta p^{2}=.06\right)$, with only a small effect size.

\section{Retention trials}

Retention trials were split into those for which children had initially received Feedback or No-feedback during the fast-mapping phase (Figure 3). Twenty-eight high-risk toddlers and twenty-eight low-risk toddlers contributed data to this measure. One-sample $t$-tests against a chance level of 0.5 revealed that only low-risk children in the Feedback trials performed significantly above chance, $(t(27)=4 \cdot 4, p<\cdot 00 \mathrm{I})$.

A mixed-factorial ANOVA with Feedback Type (Feedback vs. No-feedback) and Group yielded a significant main effect of Group, 


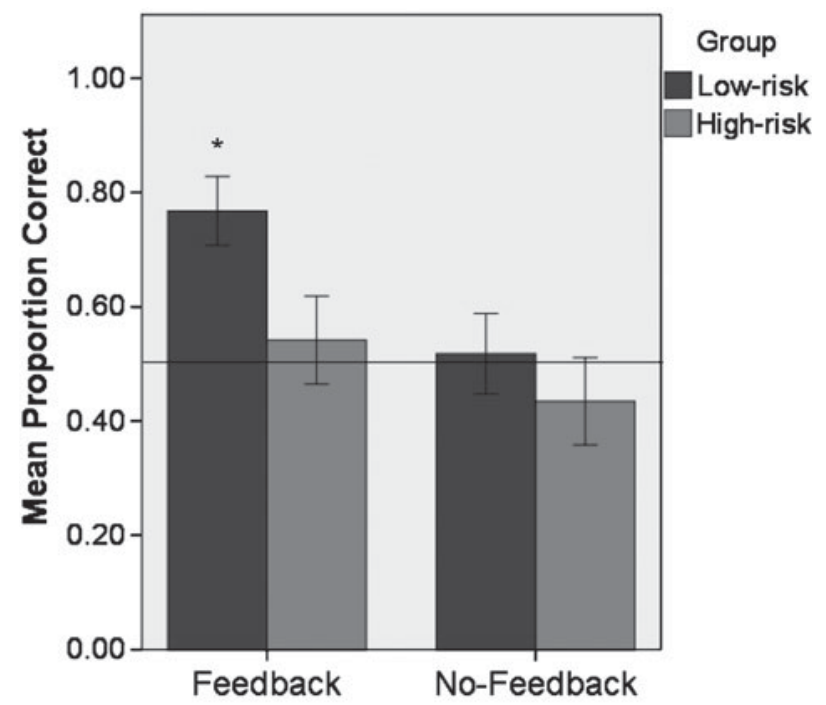

Fig. 3. Performance during the retention trials (chance level is 0.50 ; error bars $+/-I$ standard error; * indicates performance significantly above chance at the $p<0.05$ level).

$\left(F(\mathrm{I}, 54)=5 \cdot 68, \quad p=\cdot 02, \quad \eta p^{2}=\cdot \mathrm{I}\right), \quad$ with low-risk children performing better overall than the high-risk group. The main effect of Trial was also significant, reflecting an increased proportion correct on the trials with Feedback $\left(F(\mathrm{I}, 54)=5 \cdot 36, p=\cdot 02, \quad \eta p^{2}=\cdot \mathrm{I}\right)$. There was no significant interaction between Trial and Group.

\section{Type of feedback}

Not all participants contributed both correct and incorrect trials (some participants were always correct or always incorrect in their choices). Because we could not run ANOVAs incorporating both Feedback type (Feedback versus No-feedback) and Initial response (correct, incorrect), we decided to estimate the effect of Feedback Type on initially correct (i.e. reinforced) and initially incorrect (i.e. corrected) trials, separately. Different numbers of participants contribute data to these analyses.

In order to determine whether memory for a word was above chance performance, we carried out one-sample $t$-tests, looking at whether Feedback or No-feedback on choices that were initially correct or incorrect resulted in above chance memory for the word. Data from twenty low-risk and ten high-risk toddlers contributed initially incorrect trial data. Eighteen low-risk and nineteen high-risk participants contributed data for the analysis of initially correct choices. Both low-risk and high-risk infants were 

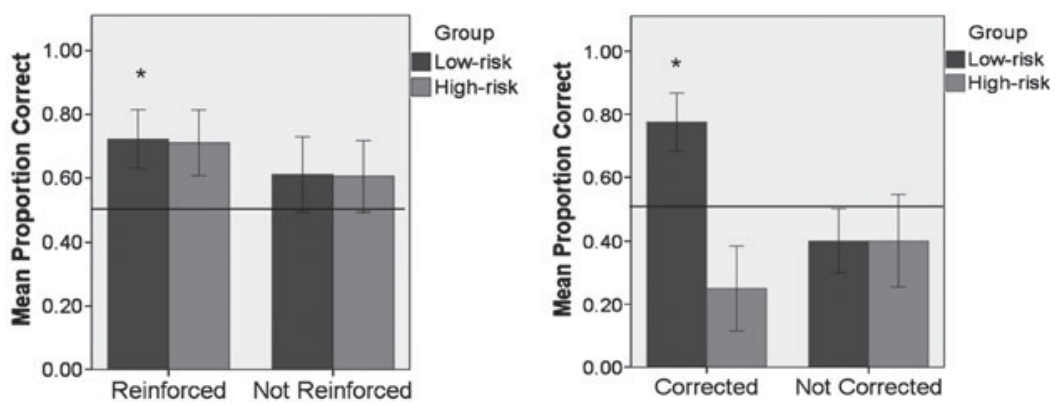

Fig. 4. Performance during the retention trials, depending on whether the feedback was reinforcing or correcting children's initial choices (chance level is 0.50 ; error bars $+/-$ I standard error; * indicates performance significantly above chance at the $p<.05$ level).

at chance performance when given no feedback, irrespective of their initial choices. Low-risk children showed above chance retention performance given feedback, for both correction $(t(\mathrm{~s} 9)=3 \cdot 0, p=\cdot 008)$ and reinforcement $(t(\mathrm{I} 7)=2 \cdot 4, p=\cdot 03)$ of their initial choice. High-risk infants performed better when their initial choice was correct, rather than incorrect, but neither correction $(\mathrm{t}(9)=-\mathrm{I} \cdot 9, p=\cdot \mathrm{I})$ nor reinforcement $(t(\mathrm{I} 8)=2 \cdot 0$, $p=\cdot 06)$ led to above chance performance.

When directly comparing the effect of Feedback on initially incorrect trials, a significant main effect of Group was found $(F(\mathrm{I}, 28)=8 \cdot 4, p=\cdot .07$, $\left.\eta p^{2}=\cdot 23\right)$ suggesting that the retention of incorrect fast-mapped trials was problematic for the high-risk toddlers. Although high-risk toddlers performed particularly poorly after Feedback (see Figure 4 ), the interaction between Group and Feedback Type $\left(F(\mathrm{I}, 28)=3 \cdot 44, p=\cdot 07, \eta p^{2}=\cdot\right.$ I I $\left._{1}\right)$ was not significant, with only a small effect size. The same analysis applied to initially correct trials yielded no main effect (of Group or Feedback type) nor a significant interaction between Group and Feedback type.

\section{Relationship with receptive vocabulary size}

We were also interested in exploring which of the abilities measured in the current experimental task might relate to linguistic competency as measured by a standardized assessment of language ability; the CDI. As seen in Table 2, there was a correlation overall between performance in the Feedback trials and receptive vocabulary count. When this correlation was broken down by Group, only the performance of the high-risk children during the Feedback trials was positively correlated with receptive vocabulary. Our study demonstrates that in high-risk children, the ability to use feedback is associated with receptive vocabulary. The lack of a correlation in the lowrisk group is probably due to the smaller variability in task performance. 
FEEDBACK REQUIRED FOR VOCABULARY LEARNING

TABLE 2. Correlations between experimental performance and vocabulary size

\begin{tabular}{lcccc}
\hline CDI receptive & Familiar & Novel & Feedback & No-feedback \\
\hline Overall Corr. coef & $\cdot 08$ & $\cdot \mathrm{I} 9$ & $\cdot 3 \mathrm{I}$ & $\cdot \mathrm{I} 2$ \\
$p$ & $\mathrm{n} . \mathrm{s}$. & $\mathrm{n} . \mathrm{s}$. & $\cdot 03$ & $\mathrm{n} . \mathrm{s}$. \\
$n$ & 56 & 56 & 50 & 50 \\
Low-risk Corr. Coef & $\cdot \mathrm{I} 3$ & $-\cdot \mathrm{I} \mathrm{I}$ & $\cdot 09$ & $\cdot 29$ \\
$\mathrm{p}$ & $\mathrm{n} . \mathrm{s}$. & $\mathrm{n} . \mathrm{s}$. & $\mathrm{n} . \mathrm{s}$. & $\mathrm{n} . \mathrm{s}$. \\
$n$ & 30 & 30 & 27 & 27 \\
High-risk Corr. coef & $\cdot \mathrm{I} 8$ & $\cdot 32$ & $\cdot 44$ & $-\cdot \mathrm{I} 3$ \\
$\mathrm{p}$ & $\mathrm{n} . \mathrm{s}$. & $\mathrm{n} . \mathrm{s}$. & $\cdot 04$ & $\mathrm{n} . \mathrm{s}$. \\
$n$ & 26 & 26 & 23 & 23 \\
\hline
\end{tabular}

\section{DISCUSSION}

In our high-risk sample, as in children with ASD (Hudry et al., 2010), receptive vocabulary size was significantly smaller than that seen for low-risk controls (Table I). As previously demonstrated for older children with ASD (de Marchena et al., 20I I ; Preissler \& Carey, 2005), toddlers at high risk for ASD had no problems, in our study, using ME to find the referent of a new word. Their performance could not be discriminated from that of low-risk controls in either the Novel or Familiar word trials. While correct fast mapping in both groups was lower than the rates found by Horst and Samuelson (2008), this may be due to the fact that our task was administered mid-way through a battery of assessments.

Given no feedback on their initial choice, both groups of children performed at chance when asked to retrieve the correct referent of a newly learned word, 5 minutes later, replicating earlier findings by Horst and Samuelson (2008). However, while low-risk toddlers benefited from feedback, which brought their retention performance to a level above chance, high-risk toddlers did not show this effect. This poor performance is even more striking given that our retention task was less demanding than that used by Horst and Samuelson, where three objects were used at test, two of which had been previously labelled. The fact that high-risk toddlers could apply the ME principle suggests that the successful performance of older children with ASD shown by Preissler and Carey (2005) is not the result of a gradual learning process. This strategy seems to be available from early on in vocabulary acquisition. In contrast to their good performance in the fast-mapping trials, high-risk toddlers did not benefit from feedback for the long-term retention of word meaning.

Performance during retention trials suggests that high-risk toddlers are generally less able than controls to remember which object had previously been labelled. A separate analysis of Corrected and Reinforced choices revealed that high-risk children showed difficulties with using CORRECTIVE 
feedback to update initial incorrect word-object mappings. For initially incorrect trials, although there was no significant interaction between Trial (Feedback versus No-feedback) and group, only low-risk children showed above chance performance when being corrected. In their study of typically developing toddlers, Horst and Samuelson (2008) only analyzed retention of initially correct choices (which form the majority of choices). However, incorrect fast mapping is probably not a real-life rarity in word learning, and feedback becomes of even greater importance in this situation. The literature on how children update initially incorrect choices is still scarce. Interestingly, and against expectations, in a study investigating learning in typically developing older children, performance in a fact-acquisition task was not affected by initial incorrect guessing (Kang, Pashler, Cepeda, Rohrer, Carpenter \& Mozer, 20 I I ), suggesting that self-generated hypotheses are typically easily overwritten by explicitly taught information, at least in typical populations. The same can be seen here in low-risk controls, who reach similar performance levels after feedback, for both initially correct and incorrect choices (Figure 4 ).

What could explain the lesser reliance on feedback in general and more particularly on corrective feedback, in the case of high-risk toddlers? The type of intervention children received upon their initial choice confounded feedback with ostensive labelling, any of the two being potentially problematic in ASD. Children and adolescents with ASD are often described as lacking cognitive flexibility (Goldstein, Johnson \& Minshew, 200I; Kleinhans, Akshoomoff \& Delis, 2005) which could prevent them from easily updating information. However, recent studies using card sorting, where the sorting rule had to be updated repeatedly, did not put children with ASD at a disadvantage (Dichter, Radonovich, Turner-Brown, Lam, Holtzclaw \& Bodfish, 2009; Poljac et al., 2010). Alternatively, toddlers at high risk for ASD might give less weight to information gained from others, through labelling, than to self-generated hypotheses. Children's object choices in the ME paradigm are the result of a hypothesis testing strategy, where each hypothesis (i.e. possible novelword referent) is assigned a certainty level (Horst, Scott \& Pollard, 2010). The corrective effect of feedback, in typical populations, may therefore be due to an increased certainty for an ostensively labelled object referent. Difficulties with social interaction, which manifest as either decreased responsiveness to social cues or a lack of initiation of social interaction, are defining characteristics of ASD (Lord et al., 2000) and children at high-risk for ASD have also been shown to rely less on ostensive and referential cues for word learning (Gliga et al., in press; Parish-Morris, Hennon, Hirsh-Pasek, Golinkoff \& Tager-Flusberg, 2007). It is therefore possible that the high-risk toddlers in this study ignored the socially conveyed information, or did not appreciate the certainty value of the ostensive 
feedback they received regarding their choices. Our current study cannot tease apart these two possibilities; whether our results are due to a lack of child flexibility in word learning, or differential weighting of self-generated versus taught information. Future studies will have to address this by comparing the effects of ostensive versus non-ostensive corrective evidence.

These findings are timely because they shed light on the role played by referent selection strategies on vocabulary learning in general. Lexical constraints or heuristics like ME have been described as the cause of the acceleration in word acquisition taking place towards the end of the second year of life. Markman, one of the first researchers to explore children's use of ME, states that: 'At some point the learning changes and becomes very rapid. This new fast form of learning may be made possible by the emergence, consolidation or learning of such constraints on word learning' ( I99 I, p. 8o). However, recent computational models of vocabulary growth do not support THE NEED FOR specialized processes (McMurray, 2007). Our own findings also suggest that the ability to apply the ME principle is not SUFFICIENT for vocabulary growth. While contexts in which only one novel object is present when a new word is heard might serve to move word learning forward, through processes of hypothesis-generation regarding possible referents, these hypotheses must either be retested or otherwise directly confirmed through feedback in order to result in successful word learning. It is retention performance following feedback rather than fast-mapping performance that correlates with children's receptive vocabulary size.

Although causation cannot be inferred from correlations, we think it is unlikely that lower retention in the high-risk group is due to lower language scores. We were careful to match participants in non-verbal IQ because memory itself (ability tested by the visual reception scale of the Mullen) could have affected performance in the retention test. All children, however, could follow simple commands like 'Can you give me the moxi?', and further, both high- and low-risk children showed excellent performance in the fast-mapping trials. We therefore believe it is more likely that children's ability to use feedback is driving their vocabulary acquisition, explaining partially the difference in vocabulary size between low- and high-risk participants. Although we show that the ability to learn from feedback contributes to word retention, we do not expect this factor to be unique in explaining vocabulary growth in children with ASD or in those at high risk thereof. The child's willingness to take part in social interaction, their request for lexical information, and their ability to extract lexical rules, all of which are problematic in these populations (e.g. Eigsti, de Marchena, Schuh \& Kelley, 20 I ; Tek, Jaffery, Fein \& Naigles, 2008) are probably contributing factors. Future studies will have to assess their relative contribution for language acquisition in typical and atypical development. 


\section{REFERENCES}

Baron-Cohen, S., Baldwin, D. A. \& Crowson, M. (I997). Do children with autism use the speaker's direction of gaze strategy to crack the code of language? Child Development 68(I), 48-57.

Bolton, P., Macdonald, H., Pickles, A., Rios, P., Goode, S., Crowson, M., et al. (I994). A case-control family history study of autism. Fournal of Child Psychology and Psychiatry 35(5), 877-900.

Carey, S. \& Bartlett, E. (1978). Acquiring a single new word. Paper presented at the Stanford Child Language Conference.

Charman, T., Drew, A., Baird, C. \& Baird, G. (2003). Measuring early language development in preschool children with autism spectrum disorder using the MacArthur Communicative Development Inventory (Infant Form). Fournal of Child Language 3o(r), $213-36$.

Constantino, J. N., Zhang, Y., Frazier, T., Abbacchi, A. M. \& Law, P. (20ro). Sibling recurrence and the genetic epidemiology of autism. American fournal of Psychiatry 167, I 349-56.

Dale, P. S. \& Fenson, L. (1996). Lexical development norms for young children. Behavioral Research Methods, Instruments, \& Computers 28, $125^{-27}$.

Davidson, D., Jergovic, D., Imami, Z. \& Theodos, V. (I997). Monolingual and bilingual children's use of the mutual exclusivity constraint. Fournal of Child Language 24(I), 3-24.

de Marchena, A., Eigsti, I. M., Worek, A., Ono, K. E. \& Snedeker, J. (20Ir). Mutual exclusivity in autism spectrum disorders: Testing the pragmatic hypothesis. Cognition II9(I), 96-II3.

Dichter, G. S., Radonovich, K. J., Turner-Brown, L. M., Lam, K. S., Holtzclaw, T. N. \& Bodfish, J. W. (2009). Performance of children with autism spectrum disorders on the dimension-change card sort task. Fournal of Autism and Developmental Disorders 4o(4), $44^{8}-56$.

Eigsti, I-M, de Marchena, A. B., Schuh, J. M. and Kelley, E. (20 I). Language acquisition in autism spectrum disorders: A developmental review. Research in Autism Spectrum Disorders 5, 68 I-9I.

Fenson, L., Dale, P. S., Reznick, J. S., Thal, D., Bates, E., Hartung, J. P., et al. (1993). MacArthur Communicative Development Inventories. Baltimore: Paul H. Brookes Publishing Co.

Fletcher-Watson, S., Leekam, S. R., Benson, V., Frank, M. C. \& Findlay, J. M. (2009). Eye-movements reveal attention to social information in autism spectrum disorder. Neuropsychologia 47(I), 248-57.

Fombonne, E. (2003). Epidemiological surveys of autism and other pervasive developmental disorders: An update. Fournal of Autism and Developmental Disorders 33(4), 365-82.

Gliga, T., Elsabbagh, M., Hudry, K., Charman, T. \& Johnson, M. \& the BASIS Team (in press). Gaze-following, gaze reading and word learning in children at-risk for autism. Child Development.

Goldstein, G., Johnson, C. R. \& Minshew, N. J. (200I). Attentional processes in autism. Fournal of Autism and Developmental Disorders 3I(4), 433-40.

Goodman, R., Ford, T., Richards, H., Gatward, R. \& Meltzer, J. (2000). The Development and Well-Being Assessment: Description and initial validation of an integrated assessment of child and adolescent psychopathology. Fournal of Child Psychology and Psychiatry 4r, (5), 645-55.

Halberda, J. (2003). The development of a word-learning strategy. Cognition 87(I), B23-34.

Hollich, G. J., Hirsh-Pasek, K., Golinkoff, R. M., Brand, R. J., Brown, E., Chung, H. L., et al. (2000). Breaking the language barrier: An emergentist coalition model for the origins of word learning. Monographs of the Society for Research in Child Development 65(3).

Horst, J. S. \& Samuelson, L. K. (2008). Fast mapping but poor retention by 24 -month-old infants. Infancy $\mathbf{1 3}(2)$, I28-57. 
Horst, J. S., Scott, E. J. \& Pollard, J. A. (2010). The role of competition in word learning via referent selection. Developmental Science 13(5), 706-7I 3.

Houston-Price, C., Plunkett, K. \& Duffy, H. (2006). The use of social and salience cues in early word learning. Fournal of Experimental Child Psychology 95(I), 27-55.

Hudry, K., Leadbitter, K., Temple, K., Slonims, V., McConachie, H., Aldred, C., et al. (2010). Preschoolers with autism show greater impairment in receptive compared with expressive language abilities. International Fournal of Language and Communication Disorders 45(6), $68 \mathrm{I}-90$.

Kang, S. H., Pashler, H., Cepeda, N. J., Rohrer, D., Carpenter, S. K. \& Mozer, M. C. (20II). Does incorrect guessing impair fact learning? Fournal of Educational Psychology $\operatorname{ro3}(\mathrm{I}), 48-59$.

Kleinhans, N., Akshoomoff, N. \& Delis, D. C. (2005). Executive functions in autism and Asperger's disorder: Flexibility, fluency, and inhibition. Developmental Neuropsychology 27(3), 379-40I.

Leekam, S. R. \& Ramsden, C. A. (2006). Dyadic orienting and joint attention in preschool children with autism. Fournal of Autism and Developmental Disorders 36(2), I 85-97.

Lord, C., Risi, S., Lambrecht, L., Cook, E. H., Jr., Leventhal, B. L., DiLavore, P. C., et al. (2000). The autism diagnostic observation schedule-generic: A standard measure of social and communication deficits associated with the spectrum of autism. Fournal of Autism and Developmental Disorders 3o(3), 205-223.

Lord, C., Rutter, M. L. \& LeCouteur, A. (1994). The autism diagnostic interview-revised: A revised version of a diagnostic interview for caregivers of individuals with possible pervasive developmental disorders. Fournal of Autism and Developmental Disorders 24, 659-85.

Markman, E. M. (I99I). The whole-object, taxonomic, and mutual exclusivity assumptions as initial constraints on word meanings. In S. A. Gelman \& P. Byrnes (eds), Perspectives on language and thought: Interrelations in development, 72-106. Cambridge: Cambridge University Press.

Markman, E. M. \& Wachtel, G. F. (1988). Children's use of mutual exclusivity to constrain the meanings of words. Cognitive Psychology 2o(2), I 2 I-57.

Markman, E. M., Wasow, J. L. \& Hansen, M. B. (2003). Use of the mutual exclusivity assumption by young word learners. Cognitive Psychology 47(3), 24I-75.

Mather, E. \& Plunkett, K. (2010). Novel labels support IO-month-olds' attention to novel objects. Fournal of Experimental Child Psychology ro5, (3), 232-42.

Mather, E. \& Plunkett, K. (20II). Mutual exclusivity and phonological novelty constrain word learning at 16 months. Fournal of Child Language 38(5), 933-50.

McMurray, B. (2007). Defusing the childhood vocabulary explosion. Science 3I7(5838), 63 I.

Merriman, W. E. \& Schuster, J. M. (I99I). Young children's disambiguation of object name reference. Child Development 62(6), I288-30 .

Mullen, E. M. (1995). Mullen Scales of Early Learning (AGS edn). Circle Pines, MN: American Guidance Service Inc.

Ozonoff, S., Rogers, S. J., Farnham, J. M. \& Pennington, B. F. (1993). Can standard measures identify subclinical markers of autism? Fournal of Autism and Developmental Disorders 23(3), 429-4I.

Parish-Morris, J., Hennon, E. A., Hirsh-Pasek, K., Golinkoff, R. M. \& Tager-Flusberg, H. (2007). Children with autism illuminate the role of social intention in word learning. Child Development 78(4), i $265-87$.

Piven, J., Palmer, P., Landa, R., Santangelo, S., Jacobi, D. \& Childress, D. (1997). Personality and language characteristics in parents from multiple-incidence autism families. American Fournal of Medical Genetics 74, 398-4I I.

Poljac, E., Simon, S., Ringlever, L., Kalcik, D., Groen, W. B., Buitelaar, J. K., et al. (20I0). Impaired task switching performance in children with dyslexia but not in children with autism. Quarterly Fournal of Experimental Psychology (Colchester) 63, (2), $40 \mathrm{I}-4 \mathrm{I} 6$.

Preissler, M. A. \& Carey, S. (2005). The role of inferences about referential intent in word learning: Evidence from autism. Cognition $\mathbf{9 7}(\mathrm{I}), \mathrm{B}_{1} 3^{-2} 3$. 
Quine, W. V. O. (I960). Word and Object. Cambridge, MA: MIT Press.

Rogers, S. J. (2009). What are infant siblings teaching us about autism in infancy? Autism Research 2(3), 125-37.

Rutter, M., Bailey, A. \& Lord, C. (2003). SCQ: The Social Communication Questionnaire. Manual. Los Angeles, CA: Western Psychological Services.

Tager-Flusberg, H., Paul, R. \& Lord, C. E. (2005). Language and communication in autism. In F. Volkmar, R. Paul, A. Klin \& D. J. Cohen (eds), Handbook of autism and pervasive developmental disorder, 3rd edn, vol. I, 335-64. New York: Wiley.

Tek, S., Jaffery, G., Fein, D. and Naigles, L. R. (2008). Do children with autism spectrum disorders show a shape bias in word learning? Autism Research I, 208-222.

Toth, K., Dawson, G., Meltzoff, A. N., Greenson, J. \& Fein, D. (2007). Early social, imitation, play, and language abilities of young non-autistic siblings of children with autism. Fournal of Autism and Developmental Disorders 37(1), I45-57.

World Health Organisation (WHO) (1993). Mental disorders: A glossary and guide to their classification in accordance with the Ioth revision of the international classification of diseases: Research diagnostic criteria $(I C D-I O)$. Geneva: WHO.

Woodward, A. L. \& Hoyne, K. L. (I999). Infants' learning about words and sounds in relation to objects. Child Development $\mathbf{7 0}(\mathrm{I}), 65-77$.

Yirmiya, N., Gamliel, I., Pilowsky, T., Feldman, R., Baron-Cohen, S. \& Sigman, M. (2006). The development of siblings of children with autism at 4 and I4 months: Social engagement, communication, and cognition. Fournal of Child Psychology and Psychiatry $47(5), 5$ I I-23.

Yirmiya, N., Gamliel, I., Shaked, M. \& Sigman, M. (2007). Cognitive and verbal abilities of 24- to 36-month-old siblings of children with autism. Fournal of Autism and Developmental Disorders 37(2), 218-29. 